Research Article

\title{
A Study on Evaluation of Laqshay in Andaman
}

\author{
Vivin Vincent', MK Saha ${ }^{2}$ \\ ${ }^{1}$ Associate Professor, Department of Community Medicine, ANIMS, Port Blair. \\ ${ }^{2}$ Professor, Department of Obstetrics and Gynaecology, ANIMS, Port Blair. \\ DOI: https://doi.org/10.24321/2454.8642.201913
}

I $\quad \begin{array}{lllll}\mathbf{N} & \mathbf{F} & \mathbf{O}\end{array}$

Corresponding Author:

MK Saha, Department of Community Medicine, ANIMS, Port Blair.

E-mail Id:

diraniims@gmail.com

Orcid Id:

https://orcid.org/0000-0001-6859-9484

How to cite this article:

Vincent V, Saha MK. A Study on Evaluation of Laqshay in Andaman. Rec Adv Path Lab Med 2019; 5(3): 1-4.

Date of Submission: 2019-06-29

Date of Acceptance: 2019-09-07

\section{$\begin{array}{llllllll}\mathbf{A} & \mathbf{B} & \mathbf{S} & \mathbf{T} & \mathbf{R} & \mathbf{A} & \mathbf{C} & \mathbf{T}\end{array}$}

Background: Respectful maternity care plays a major role in maintaining wellbeing of the mother and newborn, and ensures positive cognitive and emotional development of the babies later in life.

Objectives: Aim and objective of the study states to evaluate the implementation of respectful maternity Care and to evaluate the implementation of new born care guidelines in laqshay.

Materials and Methods: A cross sectional study was designed to meet the objectives on this study between January to April 2019 using a structured questionnaire.

Result: $95 \%$ of study population were not allowed to walk or change position during labour. Around $56.7 \%$ reported that direct pushing was done. Only $22 \%$ of mothers were allowed to choose their position of comfort. None were allowed to have a birth companion and all mothers were ensured privacy during labour.

Conclusion: Repeated counselling/ reinforcement to the staff members and surprise frequent visits by authorities concerned to the labour room will still improve the respectful maternal care.

Keywords: Babies, Laqshay, Maternity

\section{Introduction}

Government of India has launched "LaQshya" (Labour room Quality improvement Initiative) to improve quality of care in labour room and maternity operation theatres in public health facilities. It's a multipronged approach focused at Intrapartum and immediate postpartum period.

There has been a significant increase in the number of institutional deliveries after the launch of the NHM. But this increase has not led to expected improvement in maternal and neonatal health indicators.

Approximately $46 \%$ maternal deaths, over $40 \%$ stillbirths and $40 \%$ new born deaths take place on the day of the delivery. Pregnant women often undergo rude and uncourteous treatment at the health facilities.
Respectful maternity care defined as "respect for women's autonomy, dignity, feelings, privacy, choices, freedom from ill treatment \& coercion and consideration for personal preferences including option for companionship during the maternity care" not only contributes in ensuring positive outcomes for the mothers and new-borns, but also supports cognitive development of the babies later in the life. ${ }^{1}$

Laqshay program has been implemented by the Government of India under National Health mission to provide a transformed care during postpartum period to both mother and the newborn. Determinants impacting health and wellbeing of mothers \& new-borns during the intrapartum \& immediate post-partum period. Corrective actions including emotional support have been enlisted. This study has been planned to evaluate the changes in implementation of that transformed care. ${ }^{1,2}$ 


\section{Aims and objectives}

Aim and objective of the study states:

- To evaluate the implementation of respectful maternity Care

- To evaluate the implementation of new born care guidelines in laqshay

\section{Materials and Methods}

A cross sectional study was designed to meet the objectives on this study. The study was conducted between January to April 2019 in the Obstetrics unit at GB pant Hospital, ANIMS, Port Blair. Postpartum mothers on the day of their discharge (after getting their discharge summary) were interviewed using a structured questionnaire regarding the above-mentioned objectives. The Participants were briefed about the objectives of the study and data collected after obtaining a written informed consent. The participants were also assured of the confidentiality of the information.

The data collection tool used for the study was an interviewer administered questionnaire which comprised only of the components of the program. All data were entered in excel spread sheet, analysed and interpreted in term of frequencies and percentages. SPSS software was used for find the associations between the variables. Ethical clearance for the study was obtained from the hospital Institution Ethics Committee before the commencement of the study.

\section{Result}

Around $51 \%$ of study population were in the age group of 20-25 years. Around $80 \%$ of study population were either Primigravida or second gravida (Table 1).

Table 2 shows that, 95\% of study population were not allowed to walk or change position during labour. Around $56.7 \%$ reported that direct pushing was done. Only $22 \%$ of mothers were allowed to choose their position of comfort. None were allowed to have a birth companion and all mothers were ensured privacy during labour. Around $75 \%$ of mothers were motivated for early initiation of breast feeding. Around $60 \%$ reported that frequent vaginal examination was done. $30 \%$ of mothers reported they had encountered verbal and physical abuse during parturition. $4.42 \%$ were compelled to do out of pocket expenditure.

Table I.Distribution of study population according to age group and gravida status

\begin{tabular}{|c|c|c|c|c|}
\hline Age group (years) & Primigravida No (\%) & Gravida 2 No (\%) & Gravida 3 No (\%) & >3 No (\%) \\
\hline$<20$ & $38(20.54)$ & $21(14.78)$ & 0 & 0 \\
\hline $20-25$ & $113(61.08)$ & $69(48.60)$ & $12(24)$ & $1(14.28)$ \\
\hline $25-30$ & $29(15.68)$ & $21(14.79)$ & $5(10)$ & $3(42.86)$ \\
\hline $30-35$ & $4(2.16)$ & $27(19.02)$ & $21(42)$ & $1(14.28)$ \\
\hline$>35$ & $1(1.08)$ & $4(2.81)$ & $12(24)$ & $2(28.56)$ \\
\hline Total & 185 & 142 & 50 & 7 \\
\hline
\end{tabular}

Table 2.Distribution of the Study population according the Respectful Care Objectives of LAQSHAY Program

\begin{tabular}{|c|c|c|c|c|c|}
\hline \multirow{2}{*}{ S. No. } & Parameter assessed & \multicolumn{2}{|c|}{ Yes } & \multicolumn{2}{c|}{ No } \\
\cline { 3 - 6 } & Frequency & Percentage & Frequency & Percentage \\
\hline 1. & $\begin{array}{c}\text { Encouraged you to walk, change position in } \\
\text { labour room }\end{array}$ & 19 & 4.95 & 365 & 95.05 \\
\hline 2. & Did direct pushing & 218 & 56.77 & 166 & 43.23 \\
\hline 3. & Allowed to choose position of comfort for & 22 & 5.73 & 362 & 94.27 \\
\hline 4. & Allowed to have a birth companion during labour & 0 & 0 & 384 & 100 \\
\hline 5. & Was motivated and assisted in early initiation of \\
breast feeding & 287 & 74.73 & 97 & 25.27 \\
\hline 6. & Frequent vaginal examination was done & 231 & 60.15 & 153 & 39.85 \\
\hline 7. & Privacy was provided during intrapartum period & 384 & 100 & & 0 \\
\hline 8. & Was the baby placed on your abdomen & 104 & 27.08 & 280 & 72.92 \\
\hline 9. & Verbal and physical abuse during intrapartum & 118 & 30.72 & 266 & 69.28 \\
\hline 10 & Did few out of pocket expenditure & 17 & 4.42 & 367 & 95.58 \\
\hline
\end{tabular}




\section{Discussion}

Worldwide, about 140 million women give birth every year. Whilst much is known about the clinical management of labour and childbirth, less attention is paid to the post-partal medical advice, so as to make women feel safe, comfortable and positive about the experience.

Recent years WHO and Indian government emphasises on respectful maternal care not only for ensuring positive outcomes for the mothers and new-borns, but also supports cognitive development of the babies later in the life.

Providing RMC is a human right-based approach to reduce maternal morbidity and mortality. RMC can improve the experience of labour and childbirth, thereby assuring equality of health..$^{2-4}$

In spite of all the measures taken, still $95 \%$ of mothers were not allowed to walk or change position. Only $22 \%$ of mothers were allowed to choose their position of comfort. Gupta et $\mathrm{al}^{5}$, in his systematic review has clearly demonstrated the need for choosing their own position of comfort. Salvatore et $\mathrm{al}^{6}$ in Italy and Jonge et $\mathrm{al}^{7}$ from Netherlands have also demonstrated similar results.

Though WHO Recent evidence suggests that direct pushing has no added advantage compared to spontaneous delivery, ${ }^{8}$ $57 \%$ of mothers reported direct pushing.

A meta-analysis done on 51 studies from 22 countries, showed that labour companions contribute significantly in supporting mothers, by providing good care and assistance during the process of parturition and aid in bridging communication between mother in labour and the health care providers.

Birth companions provide emotional support and encouragement to maintain mobility during labour, along with non-pharmacological pain relief measures like massage and meditation..$^{9,10}$ Inspite of which none were allowed to have a birth companion.

Initiation of breast feeding within one hour of birth gives the newborn the best chance to survive, grow and develop to their full potential, making it an irreplaceable element of essential newborn care. Early initiation and better breastfeeding practices could save the lives of more than 800,000 children under 5 every year, the vast majority of whom are under six months of age. Beyond survival, there is growing evidence that breastfeeding boosts children's brain development and provides protection against overweight and obesity. ${ }^{11,12}$ In our study, $25 \%$ of mothers reported late initiation of breast feeding. 97 mothers reported that initiation of breast feeding was delayed. Of these 97 mothers around $85 \%$ underwent caesarean section and hence the initiation was delayed.

In spite of repeated training and counselling, 30\% have reported verbal and physical abuse and $60 \%$ reported frequent vaginal examination. WHO recommendation insists on restricting the frequency and total number of vaginal examinations. This is particularly crucial in situations where there are other risk factors for infection (e.g. prolonged rupture of amniotic membranes and long duration of labour). ${ }^{13}$

\section{Recommendation}

Even after two years of implementation of Laqshay, still few parameters has to been improved. Repeated counselling/ reinforcement to the staff members and surprise frequent visits by authorities concerned to the labour room will still improve the scenario.

\section{Conflict of Interest: None \\ References}

1. Labour room quality improvement initiative. National Health Mission. 2017. Cited 2019 June 23. Available from: http://nhsrcindia.org/sites/default/ files/LaQshya-\%20Labour\%20Room\%20Quality\%20 Improvement\%20Initiative\%20Guideline.pdf.

2. Respectful Maternity Care: The Universal rights of childbearing women. The White ribbon alliance. Cited 2019 June 19. Available from: https://www.who.int/ woman_child_accountability/ierg/reports/2012_01S_ Respectful_Maternity_Care_Charter_The_Universal_ Rights_of_Childbearing_Women.pdf.

3. WHO recommendation on respectful maternity care during labour and childbirth. 2018. Cited 2019 June 19. Available from https://extranet.who.int/rhl/topics/ preconception-pregnancy-childbirth-and-postpartumcare/care-during-childbirth/who-recommendationrespectful-maternity-care-during-labour-andchildbirth.

4. Respectful maternity care needs to be the standard for all women worldwide. Making childbirth a positive experience: New WHO guideline on intrapartum care. Cited 2019 June 19. Available from: https://www.who. int/reproductivehealth/intrapartum-care/en/.

5. Gupta JK, Hofmeyr GJ, Shehmar M. Position in the second stage of labour for women without epidural anaesthesia. The Cochrane Database of Systematic Reviews 2012; 5: CD002006.

6. Gizzo S, Di Gangi S, Noventa M et al. Women's Choice of Positions during Labour: Return to the Past or a Modern Way to Give Birth? A Cohort Study in Italy. BioMed Research International 2014, Article ID 638093, 7.

7. de Jonge A, Rijnders ME, van Diem MT et al. Are there inequalities in choice of birthing position? Sociodemographic and labour factors associated with the supine position during the second stage of labour. Midwifery 2009; 25(4): 439-448. 
8. WHO recommendation on method of pushing. 2018. Cited 2019 June 19. Available from: https:// extranet.who.int/rhl/topics/preconception-pregnancychildbirth-and-postpartum-care/care-during-childbirth/ care-during-labour-2nd-stage/who-recommendationmethod-pushing.

9. Why having a companion during labour and childbirth may be better for you. 2019. Cited 2019 June 19. Available from: https://www.who.int/reproductivehealth/ companion-during-labour-childbirth/en/.

10. WHO recommendation on companionship during labour and childbirth. 2018. Cited 2019 June 19. Available from: https://extranet.who.int/rhl/topics/ preconception-pregnancy-childbirth-and-postpartumcare/care-during-childbirth/who-recommendationcompanionship-during-labour-and-childbirth.

11. Early initiation of breastfeeding to promote exclusive breastfeeding, WHO. Cited 2019 June 19. Available from: https://www.who.int/elena/titles/early_ breastfeeding/en/.

12. Capture the moment - Early initiation of breastfeeding: the best start for every newborn World Health Organization, UNICEF. Cited 2019 June 19. Available from: https://www.unicef.org/publications/files/ UNICEF_WHO_Capture_the_moment_EIBF_2018.pdf.

13. WHO recommendation on digital vaginal examination at intervals of four hours for routine assessment of active first stage of labour in low-risk women. 2015. Cited 2019 June 19. Available from: https://extranet.who. int/rhl/topics/preconception-pregnancy-childbirthand-postpartum-care/who-recommendation-digitalvaginal-examination-intervals-four-hours-routineassessment-active-first. 